DOI: $10.38181 / 2223-2427-2020-4-18-22$

УДК:578.834.1

( Г Галимов О.В., Ханов В.О., Нагаев Ф.Р., Минигалин Д.М., Сайфуллин Р.Р., Вагизова Г.И., 2020

КЛИНИЧЕСКИЕ ПРИМЕРЫ КИШЕЧНОЙ ФОРМЫ КОРОНАВИРУСНОЙ ИНФЕКЦИИ ГАЛИМОВ О.В., ХАНОВ В.О., НАГАЕВ Ф.Р., МИНИГАЛИН Д.М., САЙФУЛЛИН Р.Р., ВАГИЗОВА Г.И. Башкирский Государственный Медицинский Университет, Российская Федерация, 450008, г. Уфа, ул. Ленина, 3

Реферат:

Работа основана на проведении анализа клинических случаев заболеваемости кишечной формой коронавирусной инфекцией в условиях клиники Башкирского государственного медицинского университета за период с апреля по ноябрь 2020 года. Целью исследования является выяснение патогенетических механизмов развития, особенностей клинического течения и действенных методов лечения данного заболевания. В приведенных клинических случаях отмечается положительный эффект от консервативной терапии, что подтверждает отсутствие необходимости в агрессивной хирургической тактике.

Ключевые слова: коронавирусная инфекция, энтерит, колит, васкулит, гиперкоагуляционный синдром.

\title{
CLINICAL EXAMPLES OF INTESTINAL FORM OF CORONAVIRUS INFECTION
}

\author{
GALIMOV O.V., KHANOV V.O., NAGAEV F.R., MINIGALIN D.M., SAIFULLIN R.R., VAGIZOVA G.I. \\ Bashkir State Medical University, Russian Federation, 450008, Ufa, 3 Lenin St.
}

\section{Abstract:}

The work is based on the analysis of clinical cases of the incidence of intestinal coronavirus infection in the conditions of the clinic of the Bashkir State Medical University for the period from April to November 2020. The aim of the study is to elucidate the pathogenetic mechanisms of development, the peculiarities of the clinical course and effective methods of treating this disease. In these clinical cases, the positive effect of conservative therapy is noted, which confirms the absence of the need for aggressive surgical tactics.

Keywords: coronavirus infection, enteritis, colitis, vasculitis, hypercoagulation syndrome.

\section{Введение}

В конце 2019 г. в Китайской Народной Республике (КНР) произошла вспышка новой коронавирусной инфекции в городе Ухань (провинция Хубэй). Всемирная организация здравоохранения 11 февраля 2020 г. определила официальное название инфекции, вызванной новым коронавирусом, - COVID-19 («Coronavirus disease 2019»). Международный комитет по таксономии вирусов 11 февраля 2020 г. присвоил официальное название возбудителю инфекции - SARS-CoV-2. Появление COVID-19 поставило перед специалистами здравоохранения задачи, связанные с быстрой диагностикой и оказанием медицинской помощи больным. В настоящее время продолжается интенсивное изучение клинических и эпидемиологических особенностей заболевания, разработка новых средств его профилактики и лечения.
Входные ворота возбудителя - эпителий верхних дыхательных путей и эпителиоциты желудка и кишечника. SARS-CoV-2 проникает в клетки главным образом через связывание белка S с рецепторами ангиотензин-превращающего фермента II (АПФ2) инфицированных клеток. Центральная роль АПФ2 в расщеплении ангиотензина I до ангиотензина II, пептида, участвующего в гомеостазе сосудов, вазомоторном тонусе и регуляции артериального давления. Рецепторы АПФ2 экспрессируются в различных клетках человека, восприимчивых к вирусной инфекции, включая эпителиальные клетки легких, тонкой кишки и толстой кишки, канальцевые клетки почек, нейрональные и глиальные клетки головного мозга, энтероциты, эндотелиальные клетки сосудов, клетки гладких мышц и кардиомиоциты. SARS-CoV-2 также использует рецепторы трансмембранной протеазы серина 2, фермента, который также 
экспрессируется в эпителиальных клетках тонкой кишки для проникновения в инфицированные клетки. Активность SARS-CoV-2 может вызывать модификации АПФ2 в кишечнике, которые повышают восприимчивость к воспалению кишечника и диарее.

Установлено, что диссеминация SARS-CoV-2 из системного кровотока или через пластинку решетчатой кости может привести к поражению головного мозга. Изменение обоняния (аносмия) у больных на ранней стадии заболевания может свидетельствовать как о поражении ЦНС вирусом, проникающим через обонятельный нерв, так и о морфологически продемонстрированном вирусном поражении клеток слизистой оболочки носа, не исключена роль васкулита.

Специфическое вирусное и вызванное цитокиновым штормом (а в более поздние сроки - возможно и аутоиммунное) повреждение эндотелия, получившее название SARS-CoV-2-ассоциированый эндотелиит, - основа характерной для COVID-19 микроангиопатии преимущственно легких, реже - других органов (миокарда, головного мозга, кишечника и др.), причем в ряде наблюдений развивается локальный легочный или системный продуктивно-деструктивный тромбоваскулит.

B патогенезе COVID-19 поражение микроциркуляторного русла играет важнейшую роль. Для поражения легких при COVID-19 характерны выраженное полнокровие капилляров межальвеолярных перегородок, а также ветвей легочных артерий и вен, со сладжами эритроцитов, свежими фибриновыми и организующимися тромбами; внутрибронхиальные, внутрибронхиолярные и интраальвеолярные кровоизлияния, являющиеся субстратом для кровохарканья, а также периваскулярные кровоизлияния.

В части наблюдений выявлены изменения и в других органах (помимо васкулита), которые можно предположительно связать с генерализацией коронавирусной инфекции: кишечнике (катаральный и геморрагический гастроэнтероколит), головном мозге и мягкой мозговой оболочке (энцефалит и менингит), сердце (миокардит), поджелудочной железе, почках, селезенке.

На основании исследований аутопсийного материала с учетом клинической картины заболевания можно выделить, как минимум, следующие клинические и морфологические маски COVID-19: сердечную, мозговую, кишечную, почечную, печеночную, диабетическую, тромбоэмболическую (при тромбоэмболии легочной артерии), септическую (при отсутствии бактериального или микотического сепсиса), микроангиопатическую (с системной микроангиопатией), кожную.
Частота осложнений COVID-19 со стороны ЖКТ колеблется в пределах 12-61\%. Согласно недавнему метаанализу 29 исследований, вызванные инфекцией нарушения функции ЖКТ включают анорексию (21\%), тошноту и/или рвоту (7\%), диарею (9\%) и боли в животе (3\%). Наличие желудочно-кишечных симптомов у пациентов с подозрением на COVID-19 связано с 70\% риском, что диагноз подтвердится. Желудочно-кишечные кровотечения в этом же исследовании наблюдались редко, несмотря на наличие таких типичных факторов риска, как ИВЛ, тромбоцитопения или системная коагулопатия.

Множество факторов оказывает влияние на появление симптомов COVID-19 со стороны ЖКТ. Первой причиной может быть непосредственное повреждение тканей вирусом, поскольку АCE2 присутствуют в железистых клетках кишечника, и белки вирусного капсида обнаруживались в эпителии желудка, двенадцатиперстной и прямой кишки, а также в железистых энтероцитах. Кроме того, гистопатологические данные о диффузном эндотелиальном воспалении в сосудах подслизистой основы тонкого кишечника и брыжеечной ишемии дают основание предположить наличие микрососудистых повреждений тонкого кишечника. Присутствие инфильтрата плазматических клеток и лимфоцитов, а также интерстициального отека в собственной пластинке желудка, двенадцатиперстной и прямой кишке пациентов может свидетельствовать о воспалительном повреждении тканей. Также была выдвинута гипотеза о том, что вызванное вирусом изменение кишечной микрофлоры может способствовать развитию желудочно-кишечных симптомов и тяжелому течению заболевания.

\section{Клинические примеры}

В своей клинической практике с апреля по ноябрь 2020 года выявлены 17 случаев потребовавшие стационарное лечение и 30 амбулаторных пациентов, перенесших в анамнезе двустороннюю полисегментарную пневмонию, вызванную SARS-CoV-2. Возраст пациентов от 20 до 40 лет 6 человек, от 40 до 60 - 9 человек, старше 60 - 2 человек. В исследовании наблюдались 9 мужчин и 8 женщин. Отношение пролеченных по поводу новой коронавирусной инфекции в стационарных и амбулаторных условиях было 70 \% к 30 \%. Жалобы, предъявляемые пациентами, были схожими, и в основном симулировали синдром острого живота. В последующем эта клиническая картина расценена, как явление перитонизма, предположительно вследствие дегидратации брюшины и мелкоточечных кровоизлияний.

По результатам ультразвукового исследования органов брюшной полости выявлена свободная жидкость в брюшной полости в зависимости от тяжести состояния, утол- 
щение стенок толстой кишки.

Исходя из жалоб пациентов на частый жидкий стул, боли в животе, повышение температуры предварительным диагнозом был острый колит. Анализируя данные, была выдвинута гипотеза кишечной формы коронавирусной инфекции, вызванной SARS-CoV-2. Острой хирургической патологии органов брюшной полости, требующей экстренного оперативного вмешательства, выявлено не было. Выбрана тактика консервативной терапии.

1) Мужчина 25 лет, поступил 29.07.2020 с жалобами на слабость, боли в животе, частый жидкий стул. Из анамнеза известно, что проходил стационарное лечение в инфекционном госпитале клиники БГМУ с 17.06.2020 г. по 22.06.2020 г - с диагнозом правосторонняя полисегментарная пневмония до 16 \% поражения. В связи с появлением вышеописанных жалоб обратился в приемно-диагностическое отделение клиники БГМУ. В ходе обследования по результатам анализа крови выявлен лейкоцитоз более 10 млн. По ультразвуковому исследованию органов брюшной полости выявлено около 500 мл свободной жидкости с перегородками, увеличение селезенки. Предварительным диагнозом приемного отделения был острый панкреатит. По компьютерной томографии органов брюшной полости внутрибрюшная количественная лимфоаденопатия, уплотнение в проекции большого сальника. Для исключения онкологического процесса взяты анализы крови на онкомаркеры, результаты в пределах нормы. В связи с отсутствием положительной динамики от консервативной терапии произведена диагностическая лапароскопия, во время которой взята проба серозного экссудата брюшной полости на бактериологический посев. Органической патологии органов брюшной полости выявлено не было. Назначена антибактериальная, противовоспалительная, дезинтоксикационная инфузионная терапия. На фоне лечения у пациента отмечалась положительная динамика, объем свободной жидкости уменьшился, снижение температуры и болевого синдрома. Курс лечения закончен, выписка с рекомендациями под наблюдение терапевта по месту жительства.

2) Женщина 56 лет, жалобы при поступлении на боли в левой подвздошной области, слабость, сухость во рту, частый (до 5 раз в сутки) кашицеобразный стул. Из анамнеза больна в течение трех суток, когда впервые появились выше указанные симптомы, самостоятельно не лечилась. 30.10.2020 в связи с ухудшением самочувствия доставлена в приемно-диагностическое отделение клиники БГМУ по линии скорой медицинской помощи. При объективном осмотре: выраженная локальная болезненность в левой подвздошной области, перитонеальные знаки отрицательные. По данным УЗИ выявлено утолщение стенок сигмовидной кишки, незначительное количество свободной жидкости в малом тазу и левой подвздошной области. По компьютерной томографии органов брюшной полости клетчатка брюшной полости в левой подвздошной области уплотнена, тяжиста. Пациентка госпитализирована в хирургическое отделение клиники БГМУ с предварительным диагнозом: Дивертикулярная болезнь сигмовидной кишки, дивертикулит. Пациентка дообследована. По данным колоноскопии - умеренная гиперемия и отечность слизистой нисходящей ободочной, сигмовидной кишки, язвенных дефектов и дивертикулов не выявлено. Заключение: колит левого фланга ободочной кишки. По результатам биопсии лейкоцитарная инфильтрация. Проводилась антимикробная, противовоспалительная, дезинтоксикацинная терапия. На фоне консервативной терапии положительная динамика, выписка под наблюдение терапевта по месту жительства.

3) Мужчина 65 лет, поступил 28.10.2020 с жалобами на частый жидкий стул до 7 раз в сутки, боли в животе, повышение температуры до 38 С, общую слабость, снижение веса на 15 кг за месяц. Вышеописанные жалобы беспокоили в течение последних нескольких месяцев. Из анамнеза 14.10.2020 выписан из COVID-госпиталя, в котором проходил лечение по поводу коронавирусной инфекции, внебольничной двусторонней полисегментарной пневмонии, тяжелой степени ДН 0-1 (вирусное поражение легких 60\%). По Ультразвуковому исследованию в брюшной полости визуализирована свободная жидкость в объеме 1000 мл, увеличенная селезенка 170^100 мм, растянутая петля кишки в правой подвздошной области и утолщение ее стенок. В плевральных полостях также визуализировалась жидкость в объеме 80 мл с обеих сторон. По анализам крови был значительный лейкоцитоз до 32 * 109 г/л, увеличение показателей С-реактивного белка > 60 мг/л; прокальцитонина > 10 нг/мл; снижение показателя общего белка до 46 г/л; изменение в коагулограмме. По компьютерной томографии органов брюшной полости также выявлено утолщение стенок толстой кишки до 2 см. Предварительным диагнозом выставлен язвенный колит. Проводилась антибактериальная, противовоспалительная, дезинтоксикационная инфузионная терапия. В динамике по ультразвуковому исследованию в брюшной полости отмечалось увеличение объема асцита до 2500 мл. Колоноскопия данному пациенту не проводилась с связи с высоким риском перфорации на фоне воспаления. Планируется проведение колоноскопии в отсроченном порядке. 
На фоне проведения консервативной терапии, включающей в себя двухкомпонентную антибактериальную терапию, гормональную терапию, инфузионную терапию. В результате диарея купирована, температура тела нормализовалась, результаты лабораторных и инструментальных методов исследований с выраженной положительной динамикой. В ходе дообследования и наблюдения диагноз язвенный колит снят. Установлен диагноз колит неясной этиологии. Состояние удовлетворительное, выписка под наблюдение терапевта по м/ж.

\section{Выводы:}

1. С нашей точки зрения, учитывая данные о возможности проникновении коронавируса через эпителий кишечника, нельзя исключить поражения эндотелий желудочно-кишечного тракта как форму заболевания, или возможно, как осложнение, дающие вышеописанную клинику.

2. Основной задачей врача-хирурга в условиях пандемии коронавирусной инфекции является умение дифференцировать острое хирургическое заболевание от проявлений коронавирусной инфекции. Учитывая данные анамнеза, клинических проявлений и результатов обследования. Выбор тактики лечения играет немаловажную роль, так как агрессивная хирургическая тактика может повлечь серьезные неблагоприятные последствия, учитывая весь патогенетический механизм коронавирусной инфекции, начиная от легочных осложнений, системного васкулита и заканчивая ДВС-синдромом.

3. Тактикой лечения в данном случае, по нашему мнению, являются препараты, применяемые для лечения коронавирусной пневмонии, и симптоматическая терапия. Терапия включает в себя противовирусные, противомикробные препараты, глюкокортикостероиды, антикоагулянты, витамины и дезинтоксикационную терапию.

\section{Заключение}

Несмотря на сотни научных публикаций и все усилия по исследованию COVID-19 за последний год, у нас все еще есть много вопросов о болезни и наиболее эффективных стратегиях лечения. Если раскрыть механизмы проникновения коронавируса в кишечник, и понять патофизиологию заболевания, мы сможем разработать новые методы лечения, направленные на восстановление эндотелия кишечника, которые могут облегчить клиническое течение кишечной формы COVID-19. Таким образом анализ повреждения эндотелия кишечника в контексте COVID-19 и изучение его профилактики, диагностики, лечения и реабилитации требует дальнейшего исследования.

\section{Список литературы/References}

1. Временные клинические рекомендации. Профилактика, диагностика и лечение новой коронавирусной инфекции (COVID-19). Версия 9 от 26.10.2020 [Temporary clinical guidelines. Prevention, diagnosis and treatment of new coronavirus infection (COVID-19). Version 9 from 26.10.2020 (In Russian)].

2. Клинические рекомендации. Геморрагическая лихорадка с почечной синдромом взрослых. 2016 [Clinical guidelines. Hemorrhagic fever with adult renal syndrome. 2016 (In Russian)].

3. Хлынова О. В., Карпунина Н. С., Василец Л. М. COVID-19 и поражение внутренних органов: что мы знаем, выходя на плато? Экспериментальная и клиническая гастроэнтерология. 2020;180(8): 4-9. DOI: 10.31146/1682-8658ecg-180-8-4-9 [Khlynova O. V., Karpunina N. S., Vasilets L. M. COVID-19 and the defeat of internal organs: what do we know when we go to the plateau? Experimental and clinical gastroenterology. 2020;180(8): 4-9. DOI: 10.31146/1682-8658-ecg-180-8-4-9 (In Russian)].

4. Коган Е. А., Березовский Ю. С., Проценко Д. Д., Багдасарян Т. Р., Грецов Е. М., Демура С. А., Демяшкин Г. А., Калинин Д. В., Куклева А. Д., Курилина Э. В., Некрасова Т. П., Парамонова Н. Б., Пономарев А. Б., Раденска-Лоповок С. Г., Семенова Л. А., Тертычный А. С. Патологическая анатомия инфекции, вызванной SARS-CoV-2. Судебная медицина. 2020;6(2):8-30. https://doi.org/10.19048/2411-8729-2020-6-28-30 [E.A. Kogan, Yu.S. Berezovsky, D.D. Protsenko, T.R. Bagdasaryan, E.M. Gretsov, Demura S.A., G.A. Demyashkin, D.V. Kalinin, A.D. Kukleva, E.V. Kurilina, T.P. Nekrasova, N.B. Paramonova, A.B. Ponomarev, S.G. Radenska-Lopovok, L.A. Semyonova, A.S. Tertychny. Pathological anatomy of the infection caused by SARS-CoV-2. Forensic medicine. 2020;6(2):8-30. https://doi.org/10.19048/2411-8729-2020-6-2-8-30 (In Russian)]

5. Арутюнов Г.П., Тарловская Е.И., Козиолова Н.А. и др. Согласованная позиция экспертов Евразийской ассоциации терапевтов по вопросам тактики ведения пациентов с коморбидной патологией, инфицированных SARS-Cov-2. Терапевтический архив. 2020; 92 (9): 108-124. DOI: 10.26442/00403660.2020.09.000703 [Harutyunov G.P., Tarlovskaya E.I., Koziolova N.A. and others. The agreed position of experts of the Eurasian Association of Therapists on the tactics of management of patients with comorbid pathology infected with SARS-Cov-2. Therapeutic archive. 2020; 92 (9): 108-124. DOI: 10.26442/00403660.2020.09.000703 (In Russian)].

6. Sonia Villapol. Gastrointestinal symptoms associated with COVID-19: impact on the gut microbiome. Houston, Texas, [PMC free article] [PubMed] [Google Scholar]. 
7. Гриневич В.Б., Кравчук Ю.А., Педь В.И., Сас Е.И., Саликова С.П. Ведения пациентов с заболеваниями органов пищеварения в период пандемии COVID-19. Клинические рекомендации научного общества гастроэнтеролов России. [Grinevich V.B., Kravchuk Yu.A., Ped V.I., Sas E.I., Salikova S.P. Management of patients with diseases of the digestive organs during the pandemic. COVID-19 Clinical recommendations of the Russian Gastroenterol Scientific Society (In Russian)].

8. Лобанова О.А., Трусоват Д.С., Руденко Е.Е., Проценко Д.Д., Коган Е.А. Патоморфология новой коронавирусной инфекции (COVID-19). M., 2020; 49. [Lobanova O.A., Trusovat D.S., Rudenko E.E., Protsenko D.D., Kogan E.A. Patomorphology of a new coronavirus infection (COVID-19). M., 2020; 49 (In Russian)].

\section{Сведения об авторах}

Галимов Олег Владимирович - д.м.н, профессор, заведующий кафедры хирургических болезней и новых технологий с курсом ИДПО, Башкирский Государственный Медицинский Университет, Российская Федерация, г. Уфа. https://orcid.org/0000-0003-4832-1682

Ханов Владислав Олегович - д.м.н., профессор кафедры хирургических болезней и новых технологий с курсом ИДПО, Башкирский Государственный Медицинский Университет, Российская Федерация, г. Уфа. https://orcid.org/0000-0002-1880-0968

Нагаев Фарит Робертович - заведующий хирургическим отделением Клиники Башкирского Государственного медицинского университета, Российская Федерация, г. Уфа. https://orcid.org/0000-0002-8338-2766

Минигалин Даниил Масхутович - аспирант кафедры хирургических болезней и новых технологий с курсом ИДПО, Башкирский Государственный Медицинский Университет, Российская Федерация, г. Уфа. https:/orcid.org/ 0000-0002-4292-1831

Сайфуллин Рустам Рашитович - аспирант кафедры хирургических болезней и новых технологий с курсом ИДПО, Башкирский Государственный Медицинский Университет, Российская Федерация, г. Уфа. https://orcid.org/0000-0003-1199-8630

Вагизова Гульназ Ильшатовна - ассистент кафедры хирургических болезней и новых технологий с курсом ИДПО, Башкирский Государственный Медицинский Университет, Российская Федерация, г. Уфа. https://orcid.org/0000-0001-7180-715X
Для корреспонденции

Вагизова Гульназ Ильшатовна - ассистент кафедры хирургических болезней и новых технологий с курсом ИДПО, Башкирский Государственный Медицинский Университет, Российская Федерация, г. Уфа. https://orcid.org/0000-0001-7180-715X

Information about authors

Galimov Oleg Vladimirovich - Dr. Sc., Professor, Head of the Department of Surgical Diseases and New Technologies with the course of IDPO, Bashkir State Medical University, Russian Federation, Ufa; https://orcid.org/0000-0003-4832-1682

Khanov Vladislav Olegovich - Dr. Sc., Professor of the Department of Surgical Diseases and New Technologies with the course of IDPO, Bashkir State Medical University, Russian Federation, Ufa; https://orcid.org/0000-0002-1880-0968

Nagaev Farit Robertovich - head of the surgical department of the Clinic of Bashkir State Medical University, Russian Federation, Ufa; https://orcid.org/0000-0002-8338-2766

Minigalin Daniil Maskhutovich - graduate student of the Department of Surgical Diseases and New Technologies with the course of IDPO, Bashkir State Medical University, Russian Federation, UF; https://orcid.org/0000-0002-4292-1831

Sayfullin Rustam Rashitovich - graduate student of the Department of Surgical Diseases and New Technologies with the course of IDPO, Bashkir State Medical University, Russian Federation, Ufa; https://orcid.org/0000-0003-1199-8630

Vagizova Gulnaz Ilshatovna - assistant of the Department of Surgical Diseases and New Technologies with the course of IDPO, Bashkir State Medical University, Russian Federation, Ufa; https://orcid.org/0000-0001-7180-715X

For correspondence

Vagizova Gulnaz Ilshatovna - assistant of the Department of Surgical Diseases and New Technologies with the course of IDPO, Bashkir State Medical University, Russian Federation, Ufa; https://orcid.org/0000-0001-7180-715X

Конфликт интересов

Авторы заявляют об отсутствии конфликта интересов.

Conflict of interest

The authors declare no conflicts of interest. 